\title{
Digital Service: Technological Agency in Service Systems
}

\author{
Daniel Pakkala \\ VTT Technical Research Centre of Finland Ltd. \\ daniel.pakkala@vtt.fi
}

\author{
Jim Spohrer \\ IBM Research - Almaden \\ spohrer@us.ibm.com
}

\begin{abstract}
This paper defines digital service in the context of technologically enhanced value co-creation between service system entities. Progress in digitalization and Artificial Intelligence (AI) is increasing the relative share of technologically enhanced value co-creation between service system entities (e.g., people, companies, nations). Highly automated technical systems increasingly act as autonomous agents, on behalf of service providers, in value co-creation interactions with the system users. Sufficient conceptualization, abstractions and modeling paradigms for research and development of this type of value co-creation are absent from the literature and introduced in this paper. The main contribution of the paper is introduction and definition of digital service and digital service membrane as fundamental concepts in service science and service systems, with directions for future research on the topic.
\end{abstract}

\section{Introduction}

Service systems have been defined as configurations of people, technology and other resources interacting via value propositions to create mutual value [1]. Further, smart service systems have been characterized as continuously improving and evolving in terms of productivity, quality, compliance and sustainable innovation in mutual value co-creation within the society [2].

The fundamental approach of service science towards technology has been as a type of resource to access in value propositions, especially as a tool for improving performance [1]. Technological agency (capacity of a technological artifact/system to act in their environment) has received less attention. The characterization of smart service systems highlights the role of cognitive technologies in value co-creation of service systems and introduces sustainability and compliance as criteria for smarter systems [2].

Progress in artificial intelligence (AI) can be categorized in terms of four roles for technology [3]:
- Assistive: human-in-the-loop, hard-wired-system

- Augmenting: human-in-the-loop, adaptive-system

- Automating: no-human-in-the-loop, hard-wired-system

- Autonomic: no-human-in-the-loop, adaptive-system

The assistive type of AI technology fits well within the traditional service science view of using technology as a tool, but the remaining three categories, namely augmenting, automating and autonomic AI technologies, imply technological agency and direct interaction with people and environment. Agency is more than merely another technological capability; it is also a subject of significant legal and philosophical debate $[4,5]$.

AI progress is gradually changing the role of technology in service systems. This progress is introducing increasing degrees of technological autonomy, automation and agency in value co-creation interactions among different types and sizes of social organizations (e.g. individuals, families, companies, cities/towns, counties and nations). The changing role of technology, from a tool towards "actor" in value cocreation, calls for new conceptualizations and abstractions towards technology in service science [6]. Therefore, new abstractions are needed to increase understanding of actors, actor relations, interaction, interfaces and context in value co-creation of smart service systems. A brief description of digital service and digital service membrane is provided below and those are defined in more detail further in the paper:

Digital service will be defined as a service executed in full by a technical system, when a user invokes a digital Information, Computing, Communication and Automation Technology (ICCAT) based system that (co-)creates the desired outcome.

Digital service membrane will be defined as a collection of digital service offerings in use and involved in advanced forms of value co-creation interactions between service system entities; the digital service membrane helps to protect the rights and to ensure the responsible interaction of entities in the long-term evolution of smart/wise service systems.

The abstraction of digital service is a first step towards understanding technology as actor (with agency) and not merely technology as tool. Digital 
service is proposed to serve as stable bridge between tool and actor views of technology. Also, the proposed concept of digital service herein can serve as an implementation-technology-independent representation and encapsulation of technical systems with agency in service science.

Why introduce the concepts of digital service and digital service membrane? The proliferation of life on earth required a membrane to encapsulate the right material ingredients in order to give rise to the first living cellular organisms [7]. One of these organisms, also known as the Last Universal Common Ancestor (LUCA), has since evolved to all known life on earth. Before the emergence of the stable cell membrane, the ingredients were there and diluted in space - but not in a contained environment favorable for evolution of living organisms. In analogy to the emergence of life on earth, the current state of the art in smart service systems is missing a stable membrane that would encapsulate technology in a way that is more favorable for sustainable co-evolution and co-operation of naturally intelligent (people and human organizations) as well as artificially intelligent (AI agents) systems in their shared environment.

Before defining digital service in Section 3, the relationship between service science and AI is presented in Section 2. Section 4 presents related work, and Section 5 presents the concluding remarks and future research directions.

\section{Service Science and AI}

In this section, the groundwork for the rest of the paper is established, for those who may be unfamiliar with service science and artificial intelligence (AI). For the purposes of this paper, service science can be summarized as the study of the evolving ecology of service system entities, their capabilities, constraints, rights, and responsibilities, including their value cocreation and capability co-elevation mechanisms [1]. Service systems are a type of socio-technical system, such as people, businesses, and nations, all with unique identities, histories, and reputations based on the outcomes of their interactions with other entities. Artificial intelligence (AI) can be defined as the study and implementation of intelligent behavior in technological artefacts to assist or augment humans, automate work/tasks, or to autonomously work and learn in adaptive environments including changing tasks [3]. Both service science and AI are concerned with the study of existing and new mechanisms, and the evaluation of mechanisms based on performance criteria in a wide range of contexts. For some AI researchers, the goal of $\mathrm{AI}$ is not simply to replicate human intelligence in a machine, but to go further, and integrate those machines (perhaps with super-human capabilities) in some way into human society with rights and responsibilities of their own. After all, civilization is the innovation that allows strong and weak, same and different to co-exist in relative harmony. In addition, people have benefitted from the work and companionship of animals throughout history (diverse species), and some AI researchers see machines, or software social organisms, as possible workers and companions as well [8].

However today, human laws do not grant rights to machines (or animals), because neither is capable of understanding human laws, and therefore unable to take full responsibility for their interactions with people in society. Instead, legal entities may own machines (and animals), and the owners take responsibility on their behalf. In fact, in spite of all the advances in AI, no AI system comes close to gaining the rights and responsibilities afforded seeing eye dogs assisting their sight-impaired companions. Nevertheless, advances in the past two decades, suggest that in another two decades such AI-enabled machines will likely exist [9].

Because of recent rapid advances in AI, the EditorIn-Chief of the INFORMS Journal of Service Science, Dr. Paul Maglio wrote [6]:

"What of real autonomous technologies, ones that go beyond what the author or creator specifically wrote-or ones that appear to have their own ability to deliberate, their own agency? The answer is that I do not know. And maybe this calls into question the foundation of our understanding of service as value cocreation. Certainly, it opens up whole new research questions concerning the nature of value cocreation and the relationship of people and technology in service systems. For example, it is not always clear what should be automated, or whether and when automation will improve overall system performance; little research addresses service design questions of what should be automated and under what conditions. INFORMS Service Science will be on the forefront of asking and answering these questions for years to come. "

This current paper begins to elaborate on this editorial comment. We also note there is considerable "hype" around this topic - so one must proceed carefully. For example, a recent headline [4] asked "What Exactly Does It Mean to Give a Robot Citizenship? It's complicated." Perhaps AI (as predictive technologies) are less of a crystal ball, and more of a mirror onto ourselves and our human biases [5].

To get to the heart of the issue, around service science and artificial intelligence, it is useful to return to the concept of competing for collaborators, with respect to species of entities and their capabilities, constraints, rights, and responsibilities [10]: 
"Understanding and characterizing the fundamental constraints on species is an important area of research for developing the theoretical foundations for service science. For example, humans have the following constraints:

1. Physical: finite life span

2. Cognitive: finite learning rate

3. Social: finite population size/density"

AI capabilities may someday allow service systems entities (especially people) to quantitatively and qualitatively challenge these fundamental constraints. In fact, AI researchers have even speculated about challenging the constraint of finite life span with the concept of weak immortality [11]. Because people have evolved with bounded rationality (e.g., limited memories, etc.), society and the rights and responsibilities of individuals has taken a particular form that we see today. Therefore, if AI changes the capabilities and constraints of service system entities, it is likely to lead to a technology-driven change in rights, responsibilities and governance of entities as well. To frame it somewhat in the common vernacular, we might say that with greater power comes greater responsibilities. The General Data Protection Regulation (GDPR) of the European Union is an example of technology-driven change in governance.

GDPR begins to specify and standardize, in a wide range of context, the rights and the responsibilities of (1) data controller (an organization that collects data from EU residents), (2) data processor (an organization that processes data on behalf of a data controller like cloud service providers), and (3) the data subject (a person based in the EU). GDPR provides an operational definition of rights and responsibilities, and penalties for failing to meet responsibilities. Citizens, data subjects, data processors, and data controllers are currently all service system entities, with well-defined rights and responsibilities. As people, businesses, and nations augment their capabilities with AI systems, some of the constraints of the past are overcome. For example, a person with an AI system that can recognize faces, owners of cars on the street, owner of building and particular properties, creates "a level of knowing" that far exceeds what has been easy for a person in the past.

In the next section, digital service is defined as a first step towards understanding the growth of technological agency in smarter service systems.

\section{Digital Service}

Progress in research and development of network and communication technologies has enabled information and computing systems to become distributed and inter-connected. Architecturally information and computing systems have transitioned from centralized, isolated, hardware specific systems into distributed interconnected hardware agnostic multi-organization systems. Regarding software architecture of the systems, the transition has been a journey from fully embedded software to componentand object-orientation [12], and finally to agent and service-orientation [13, 14]. Regarding hardware, the transition includes central supercomputers and personal computers, and connected combinations of these. The most recent waves here have been mobile, pervasive and ubiquitous computing, as well as distributed interconnected embedded computing [15].

The on-going journey in software and hardware architecture of information and computing systems has led to the current state, where the mainstream architectural approach is service-orientation, represented by micro-services based approach to systems development, integration and interconnection with high degree of virtualization, executional modularity and portability towards the hardware system via use of container technologies. However, the software and hardware infrastructure of modern computing systems and applications is becoming a highly heterogeneous mix of network connected computing clusters (clouds), individual servers, personal computers, mobile devices, gateways, sensors, controllers and actuators with real-time computing constraints. Furthermore, recent progress in machine and deep learning and its specialized hardware support, are adding to further heterogeneity [18, 19]. Deep learning models with the ability to recognize speech and images, and then recommend contextually appropriate actions, are now being integrated into software and hardware systems for a wide range of business applications.

Rapid technological change brings risks, such as a lack of analysis and modeling techniques for the people - technology interface:

- Identifying relevant stakeholders, actors and their roles in socio-technical systems as value cocreators with others is challenging [20].

- Need for new methods and tools for value-driven requirements engineering for technical systems [21].

- The causalities and metrics between value cocreated with a technical system and the related environmental footprint are not well-understood, addressable and only observable indirectly on macro-scale [22].

Having now described the need for a new conceptualization and abstraction, we will specify the context for the new abstractions of digital service and digital service membrane. 


\subsection{Service System Context}

The original definition of service systems [23] did not provide a uniform definition for the concept of 'service', but it refers to definitions given in the literature with different meanings in different contexts. In [24] the concept of 'service' is only sketched in an ontology based on definitions of [23]. Our goal here is not to provide a uniform or universal definition for 'service' as a concept. However, in order to define digital service, a quick review provides context.

Among many definitions for the word and concept of service in [25], service is defined as:

1) "assistance or benefit afforded another",

2) "a useful result or product of labor which is not a tangible commodity", and

3) "a system of labor and material aids used to accomplish some regular work or accommodation for the public: telephone service, train service, postal service."

All three definitions are complementary. The first identifies two different roles related to service: provider and receiver of assistance or benefit. These roles are also generally known as service provider and service user (or customer). The second describes service as intangible commodity, and a useful result or product of work performed by a service provider - for the service user. Service providers create benefits for service users. The third describes service as a system of labor and material aids to accomplish work.

Based on the perspectives above, a digital service can be defined as a service executed in full by a technical system, when a user invokes a digital ICCAT based system that (co-)creates the desired outcome. Per definition one, in digital service the assistance or benefit is mediated by means of ICCAT system between the service provider and service user roles. Per definition two, in digital service the work producing a result or product is done by means of automated processes based on ICCAT system. Per definition three, in digital service the system of work and material aids consists of ICCAT system, where work is carried out by executed software programs and electronic circuits over material aids of computing infrastructure, communications infrastructure and electromechanics, whereas labor is related to engineering, operation and maintenance of the ICCAT system.

Service provisioning is the process that a service provider needs to carry out in order to be able to provide an outcome for the service user, in a way that fulfils the value proposition and expectation of the service user. Per definition one, service provisioning is the process enabling a service provider to afford assistance or benefit for the service user. Per definition two and three, service provisioning includes the process of a service provider setting up the system of labor and material aids needed to provide a useful outcome for the service user.

Digital service provisioning can be defined as the process that a service provider of a digital service needs to carry out in order for the digital service to provide a useful outcome for the service user, in a way that fulfils the value proposition and expectation of the service user. Accordingly, digital service provisioning includes a service provider's interest and responsibility over the system of labor and material aids for producing, operating and maintaining ICCAT system, where executed software programs and electronic circuits carry out work over material aids (hardware) of the ICCAT system. This includes responsibility of design, development, deployment, operational management and maintenance of the digital service implementation with an ICCAT based system.

After the rationale on central terminology and concepts, we will now define and conceptualize digital service in context of smart service systems and propose that it can be used as a new abstraction and actor in smart service systems - participating in value cocreation with people. This requires approaching technology from the viewpoint of automated and autonomic systems having agency and direct interaction capabilities with people and environment. An important constraint for a digital service to be considered as a service system actor is that it must have a legal entity (person or organization) as responsible party governing the technological agency given to a technical system realizing the digital service on behalf of its provider.

Figure 1 illustrates the role of digital service as purely technologically enabled value co-creating service system actor in a smart service system.

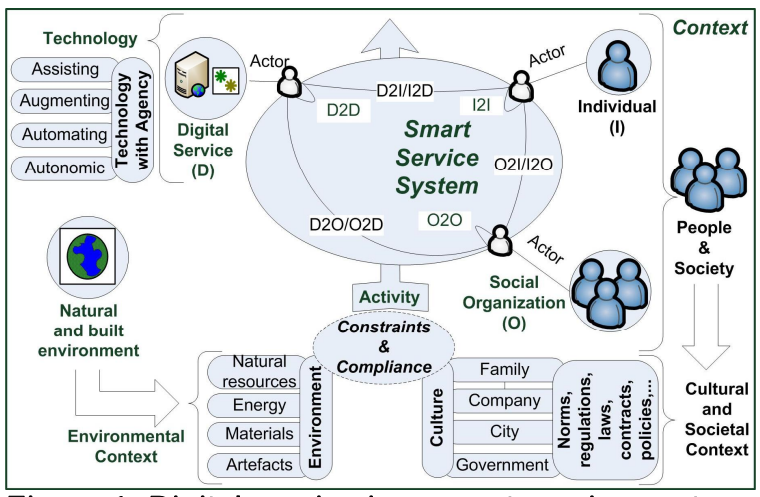

Figure 1. Digital service in a smart service system.

As illustrated, we refine the definition of smart service systems regarding the value co-creation participants (ecology, people, resources and technology 
[23]). This is done to define a framework of actor types and relations for better formalization and modeling of interactions and causalities in value co-creation activity within a smart service system. The refinements that we make to the definition of service systems [23] include:

1) Actor: a service system entity or service system resource having agency, a specified role, interaction capability and contribution within the service system's mutual value co-creation. We define 3 different actor types with 9 possible relations between the actor types:

Individual (I), a single human being as legal and operative entity in different roles towards the service system. I.e. user, citizen, employee and resident.

Social Organization (O), group of people as legal and operative entity in different roles towards the service system. I.e. provider, user, company, government, employer and owner.

Digital service (D) as autonomous and automated technical system (no human in the operational loop) with agency (on behalf of legal entity operating it) having augmentation, interaction and possible actuation capabilities with people and environment. I.e. cognitive assistant, robot, chatbot, information/ analytics/decision support service and remote control service.

Actor relations $(\mathrm{x} 2 \mathrm{x})$ constitute a framework of possible actor relations to consider in analysis, design and modeling of smart service systems. The actor relations also serve as context information and stakeholder map for individual actors/service system entities to design/align/optimize their co-operation for mutual value creation. Section 3.2 describes actor relations in more detail.

2) Activity: a domain or an area of co-operative activity amongst the actors of the smart service system defining the scope of the service system. Consists of individual actor-to-actor service interactions, which may form a service value chain.

3) Context: subset of the ecology, defined in [23], which is relevant regarding the activity of participating actors in the service system. Context can be seen as the identified relevant environment of service system and includes consideration of environmental, cultural and social context of participating actors in an activity. Identifying the relevant context of a service system enables analysis, design and monitoring of service system's compliance with related norms, contracts, laws, regulations and policies, as well as to meet the limitations set by environment in form of i.e. energy, materials, natural resources and built infrastructure. For resiliency, considering possible environmental influence (i.e. storms, earthquakes, floods, wildfires, outdoor temperature changes and animal behaviors) to service system actors and to their shared activity is an important part of the service system context.
In the framework described, value co-creation is seen as series of actor-to-actor interactions, where each interaction co-creates value for the actors (or their associated legal entities) participating in the interaction. The interactions take place in context defining the constraints and compliance requirements. The overall co-created value of a smart service system is the sum of individual actor-to-actor interactions defining the activity scope of the service system.

In dynamic non-governed service systems, the environmental and cultural constraints and performance indicators are defined by personal values of individuals, as well as by shared values and sustainability/environmental responsibility guidelines of organizations. In governed service systems, the environmental and cultural constraints and performance indicators can be agreed, monitored and governed for the overall system and used as criteria in selection of participating actors within the service system.

\subsection{Actor Relations}

As illustrated in the framework of Figure 1, we define nine possible relations $(\mathrm{x} 2 \mathrm{x})$ between actor types within smart service systems. To characterize the relations and causalities of those in more detail, we provide an example list of activities highlighting different roles that actors might have related to those:

Individual to Individual (I2I):

- Private messaging and conversation

- Helping a friend, family member or relative Individual - Organization - Individual (I2O/O2I):

- Working for a company/Providing work

- Being a citizen/Providing citizen services Individual -Digital Service - Individual (I2D/D2I):

- Health and wellness monitoring/apps and services for activity and health monitoring

- Interaction with other people/communication and social networking services

- Personal development/on-line courses and coaching services

Organization to Organization $(\mathrm{O} 2 \mathrm{O})$ :

- B2B negotiations, co-operation and contracts

- $\mathrm{R} \& \mathrm{D}$ co-operation and open innovation

- Organization's impact to other organizations, society and culture.

Organization-Digital Service-Organization

(O2D/D2O):

- Organization processes/cloud services for supporting organizational processes 
- Digitalization and automation of operations/chatbots, software robots, autonomous factories and other automated autonomous systems

- Engineering and operation of digital services/societal and cultural impact.

Digital Service to Digital Service (D2D):

- Co-operative digital services interaction /Aggregation and composition of digital services to perform larger tasks and achieve common goals (i.e. Cognitive assistant making a travel arrangement across many digital services).

- Competitive digital services interaction/ automated interaction of digital services to find interactions creating mutual benefit (i.e. AI agents in trade)

- Workflow automation/fulfilling smart contracts by configuring manufacturing, energy or logistic services (i.e. autonomous machines and factories, energy demand flexibility and autonomous vehicles).

Based on the above-described context for digital service as part of a smart service system, as an actor, we further define the concept. A service system entity is defined as dynamic configuration of resources, where at least one resource is a legal entity (focal resource) [23]. Accordingly, a digital service and its provider together form a service system entity. Figure 2 presents the key actors related to the concept and abstraction of a digital service with service system roles as stereotypes.

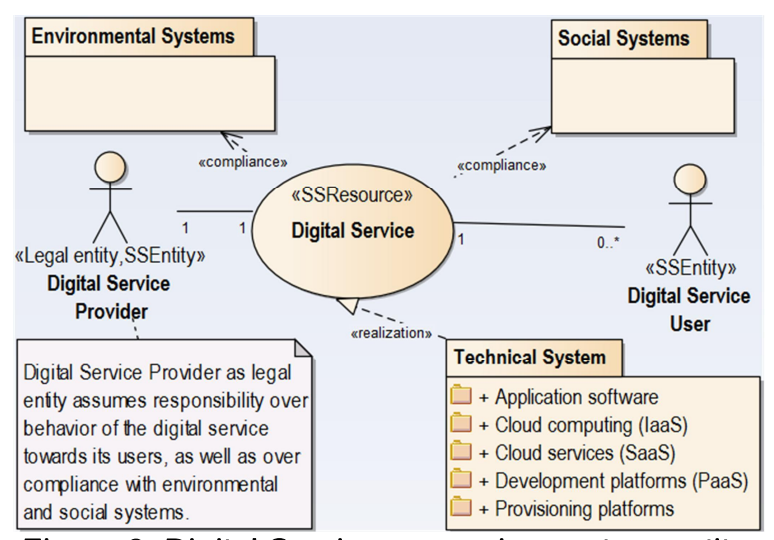

Figure 2. Digital Service as service system entity.

As illustrated, as an abstraction in service systems, we define digital service as follows:

- A service system resource with provider given and governed agency in interaction and value cocreation with other service system entities.

- Dynamic use of dynamic configuration of technology and information producing mutual value for its provider and user.
- $\quad$ Provider of the configuration is legal entity with a value proposition and is responsible for value realization and compliance with shared ecological, social and cultural context with the user.

A digital service membrane is the collection of digital service offerings involved in value co-creation interactions of service system entities, including those that enforce the rights and responsibilities of entities.

\subsection{Systems thinking and engineering}

As described in [26], systems thinking can be seen as interdisciplinary approach to discuss and explore relations between many things from different disciplines without assuming the thing necessarily being physical. In the context of smart service systems, this kind of approach is certainly useful for identifying relations and describing interaction between service system entities. As we have proposed digital service as service system resource and actor, we also shortly describe the role of this abstraction for systems thinking in order to avoid confusion on the topic.

Figure 2 illustrates the abstraction of digital service with defined associations to related systems. As illustrated in the figure, abstraction of digital service as a service system resource has relations to at least three other kind of systems, which all are highly relevant for successful value co-creation in smart service systems: environmental, social and technical systems. Regarding requirements engineering of digital services, both environmental and social systems pose constraints and requirements that should be identified and specified as requirements (functional and non-functional) for engineering of the digital service and technical system realizing it.

We see that applying multi-dimensional systems thinking on relevant environmental and social systems, focusing on actor identification, actor-to-actor interaction, shared activity and context of service system (Figure 1), is a potential approach for identifying the stakeholders, context and requirements for digital services independently of the technical system used for its realization. Technical system here is to be understood widely as the overall configuration of digital data/ information/knowledge, software, computing hardware, computer networks, devices, sensors and electromechanical actuators used for realization of a digital service as a technical system.

In the conceptualization of digital service in context of smart service systems, we introduced also the notion of shared activity of actors co-creating value in a service system (Figure 1). To clarify the notion of shared activity in applying systems thinking in smart service systems, we present an example usage of the 
digital service abstraction with two related but separate activities for value co-creation in Figure 3.

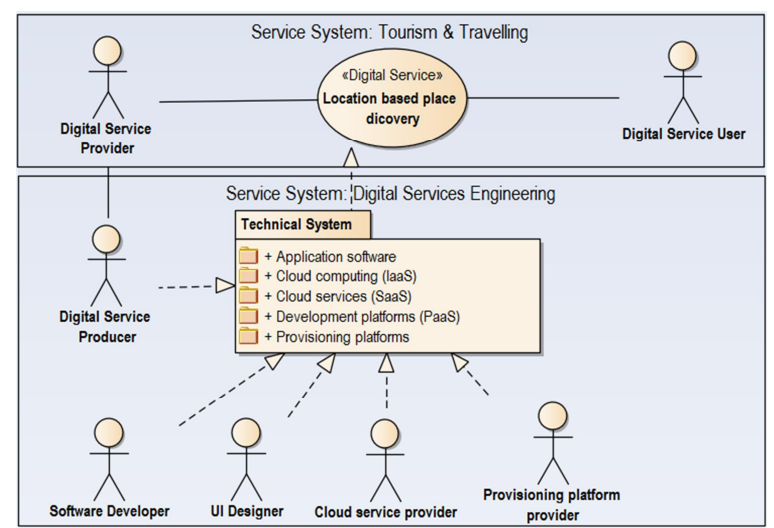

Figure 3. Example use of digital service abstraction in analysis of service systems.

As presented in the example modeling above, with the notion of activity, two separate service systems can be identified: 1) value co-creation on activity of tourism and travelling and 2) value co-creation on activity of digital services engineering. These two service systems are dependent on each other via the fact that digital services are realized by a technical system but share no other static relation with each other. Differentiating the value co-creation based on shared activity of actors also facilitates identification of related actors and their relations in more fine-grained manner. This is helpful for understanding of the ecosystems, value chains, management and possible business models around production, provisioning and use of digital services.

In the example presented in Figure 3, actor for providing digital service is separated from the actor producing it (digital service producer - responsible of engineering the technical system) in possible cooperation with additional actors. In real-word case corresponding to the example, the provisioning and production related actor roles might be fulfilled by one or more entities depending on the resources, capabilities and business models of the participating entities.

From the viewpoint of applying systems thinking, engineering of the technical system realizing a digital service provides another dimension for applying it. In order to clarify the role of the digital service abstraction in this, Figure 4 illustrates the relation and content of two different levels of engineering possible with the abstraction.

As illustrated by Figures 2 and 4, the abstraction of digital service lies in the meeting point of three different dimensions of systems thinking; 1) a dimension for analysis and design of service systems with technological agency, 2) a dimension applicable for analysis and definition of requirements for digital services independently of individual implementation technologies and 3) a dimension of systems engineering of a technical system realizing a digital service. Also, as illustrated, the digital services engineering and requirements specification precede or at least start well before the technical system engineering process, providing a starting point for it in form of digital service requirements specification. In other words, the overall value proposition, related interactions, context, stakeholders and their requirements towards the technical system should be identified and defined before starting development of the system.

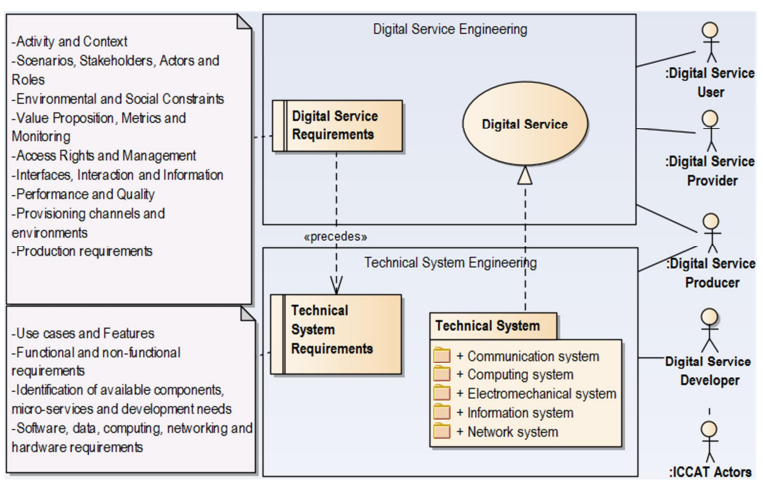

Figure 4. Two levels of engineering.

The role of digital service producer is to act as the link between the two engineering processes taking care that costs, capabilities and limitations of technology are understood in the digital service engineering process, as well as ensuring that the digital service requirement specification provides sufficient information technical system requirement specification (which is done outside the digital service engineering process).

Regarding modeling approach serving both engineering processes Model Driven Architecture and Design (MDA/MDD) [27] can be applied as the computation and platform independent models (CIM, PIM) allow modeling and specification independently of technologies in digital service engineering process. In addition, platform specific models (PSM) can be used in modeling and specification of the technical system in technical system engineering process. The MDA/MDD approach provides also stability for the value-driven digital service specification and design as rapidly evolving changes in implementation technologies are not reflected to the platform independent design and specification of the digital service. 


\subsection{Dual nature}

Figure 1 illustrates the value co-creation between digital service and other actor types in a smart service system. It is noteworthy that digital service has a dual role in terms of value co-creation:

1) A digital service can interact and co-create value directly with people (D2I/I2D and D2O/O2D interaction) on behalf of a legal entity, and

2) Digital services interact with each other co-creating mutual value in digital realm (D2D interaction) on behalf of their associated legal entities.

Accordingly, digital services may create value both in physical and cyber world interactions as illustrated in Figure 5.

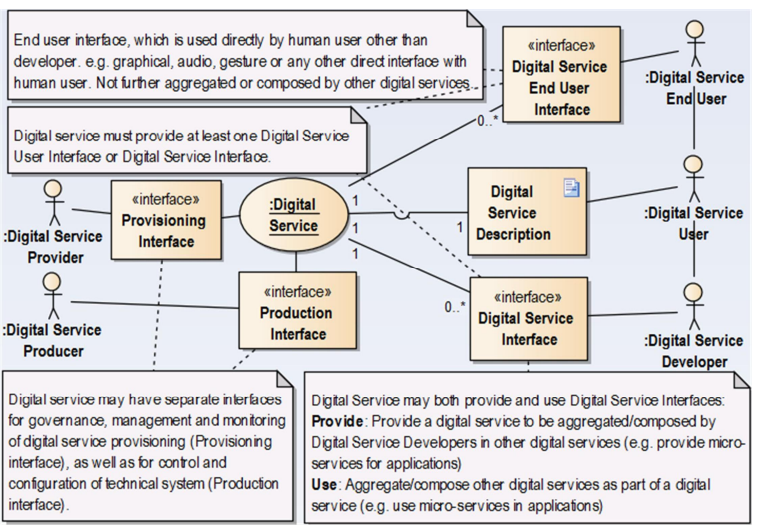

Figure 5. Digital service interfaces.

The main interfaces in value co-creation between digital service provider and user are digital service description and digital service interfaces. The digital service description is central interface in communication of the value proposition, access rights, pricing and terms of service. In addition, there are two types of digital service interfaces providing an interaction point for value co-creation with two different types of users: 1) Digital Service Interface (e.g. a micro-service endpoint) for programmatic use and 2) Digital Service End User Interface (e.g. graphical or audio interface) for direct use.

Figure 6 illustrates direct and programmatic use of digital services from the viewpoint of the two engineering processes, actors and their relations. As illustrated, the direct use of a digital service may invoke programmatic use of another digital service. In digital service engineering process, use-provide relationship analysis between actors can be applied to identify both type of uses throughout the service system of interest. Digital Service Interface is used as an implementation technology independent description for programmatic use of digital services together with the related terms of service specified in the digital service description. The concept is useful for platform independent analysis and modeling in digital service engineering process, whereas its realization as a Technical Systems Interface is under responsibility of the Technical System Engineering process with platform specific models considering the interoperability and interworking of the related technical systems.

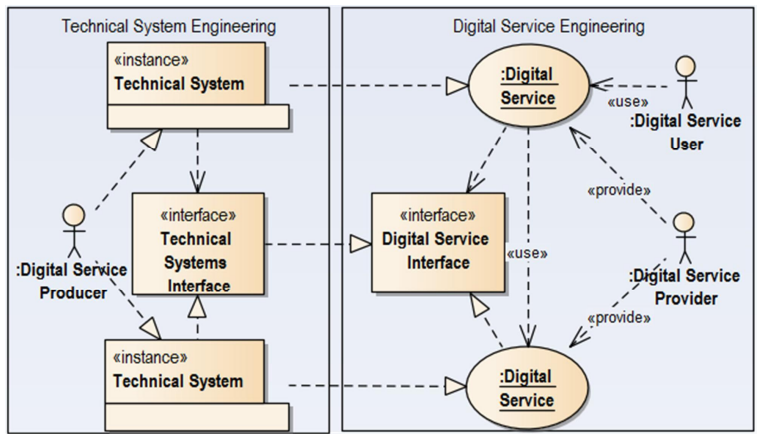

Figure 6. Direct and programmatic use.

The use-provide relationship analysis can also be useful for identifying the business relationships and models between the involved service system actors. If all the digital services in system of interest are provided by the same entity acting as digital service provider, the case corresponds to the well-known enterprise it-services management with shared service oriented technical system architecture (Enterprise SOA [14]) between the services. If the digital services are provided by different entities the technical systems interface needs to be standardized or agreed, defined and implemented between the entities in the system of interest. Examples of the latter case include integration of two information systems between two different organizations, use of cloud-based micro-services to build applications and other cases where workflows are automated across technical systems and databases of different organizations.

\section{Related Work}

In [24] definitions proposed for service science in [23] are analyzed in relation to different theories and frameworks for services in order to formalize and propose ontological foundation for research on service systems. Whereas the proposed ontological definition in [24] presents wide and unifying view on service systems, related theories and frameworks, it does not define the role of digital services within service systems.

In [28] a conceptualization of smart service systems is proposed based on smart products as physically embodied boundary objects in value co-creation 
between the provider and user of smart products and their features. In [28] 'smartness' refers to value cocreating features of the smart products between the manufacturer and product user and does not recognize the dimension of compliance to environmental and societal systems as a component of overall 'smartness' of the resulting service system.

Many of the characterizations described in [28] are useful for increasing understanding on value cocreation between smart product manufacturers and customers and are partially in line with the abstraction of digital service provided in this paper. However, our view is that using smart products or any other physically embodied boundary objects, as basis for conceptualization in smart service systems, is unnecessarily limited and complex conceptualization. The conceptualization of digital service provided in this paper can accommodate also value co-creation mediated by smart products, or any other technical systems embodied in various forms and configurations, providing also more concise and holistic view on the 'smartness' in service systems. In cases, where the interface mediating the digital service between provider and user is physically embedded (e.g. in a smart connected product), the whole end-to-end technical system involved in realization of the cocreated value is considered as the technical system realizing the digital service. If the user interface is provided as an additional software application (e.g. mobile app) - instead of or in addition to embedded interface - also the application and its development, distribution and execution environment should be seen as part of the end-to-end technical system realizing the digital service.

Fundamentals of service science and the science of service systems have been provided in $[29,30]$, which we have advanced to include technological agency. Regarding work systems, our work relates to [31] by introducing digital service as activity performing actor role performed by encapsulated automated service. Our work can also be seen adjacent to $[32,33]$ but focuses on concise definition of digital service in context of service science and smart service systems.

\section{Conclusion}

By defining digital service, a technological artefact/system with capacity to act in a service system, we have advanced the fundamentals of service science and service systems to include technological agency. The field of software and systems engineering has long struggled with finding the appropriate and useful abstractions and methodology for building technical systems that would maximize value for all the stakeholders involved. The viewpoint of value co- creation among service system entities (service science) provides a seed for further research and development of engineering and operational methodologies for digital service with increasing agency (artificial intelligence).

In our work, we have defined concept and abstraction of digital service and provided examples better connecting the fields of service science, artificial intelligence, system thinking, software engineering, systems engineering and information systems. We applied UML modeling for definition of concept and abstraction of digital service. However, future research is needed regarding feasible value-driven engineering, analysis and modeling methodologies for digital services as part of service systems. Future research is also need on applicable modeling approaches and conventions for efficiently linking the digital services engineering and technical system engineering and operating processes. Due to increasing technological agency in service systems, we also expect to see new research on governance of digital services.

\section{References}

[1] P.P. Maglio, S.L. Vargo, N. Caswell and J. Spohrer, "The service system is the basic abstraction of service science", Information Science and e-Business Management, SpringerVerlag, September 2009, pp. 395-406.

[2] H. Demirkan, J.C. Spohrer and R. Badinelli, "Introduction to the Smart Service Systems: Analytics, Cognition, and Innovation Minitrack", Hawaii International Conference on System Sciences (HICSS) Proceedings, IEEE, March 30, 2015.

[3] A.S. Rao and G. Verweij, "Sizing the prize, What's the real value of $\mathrm{AI}$ for your business and how can you capitalise?" PwC Publication, PwC, 2017, URL: https://www.pwc.com/gx/en/issues/analytics/assets/pwc-aianalysis-sizing-the-prize-report.pdf

[4] J.F. Weaver, "What Exactly Does It Mean to Give a Robot Citizenship? It's complicated." Slate.com, 2017, URL: http://www.slate.com/articles/technology/future tense/2017/ 11/what_rights_does_a_robot_get_with_citizenship.html

[5] J. Ito "AI isn't a crystal ball, but it might be a mirror." MIT Media Lab, 2018, URL: https://www.media.mit.edu/articles/ai-isn-t-a-crystal-ballbut-it-might-be-a-mirror/

[6] P.P. Maglio, "Editorial Column-New Directions in Service Science: Value Cocreation in the Age of Autonomous Service Systems." Service Science 9(1), INFORMS, March 2017, pp. 1-2. 
[7] D. Deamer, "The Role of Lipid Membranes in Life's Origin.”, Luisi PL, ed. Life, Basel, Switzerland, MDPI, March 2017, DOI:10.3390/life7010005.

[8] K.D. Forbus, "Software social organisms: implications for measuring AI progress", AI Magazine 37(1), AAAI, Spring 2016, pp. 85-90.

[9] W.B. Rouse and J.C. Spohrer, "Automating versus augmenting intelligence", Journal of Enterprise Transformation, Taylor \& Francis Group, 2018, pp. 1-21. DOI: $10.1080 / 19488289.2018 .1424059$

[10] J. Spohrer, S.K. Kwan and R.P. Fisk, "Marketing: a service science and arts perspective", Handbook of service marketing research, Ed. Rust and Huang., EE Publishing, 2014, pp. 489-526. DOI:10.4337/9780857938855.00033

[11] D.B. Lenat, "WWTS (what would Turing say?)", AI Magazine 37(1), AAAI, April 2016, pp. 97-101.

[12] O. Nierstrasz, S. Gibbs, and D. Tsichritzis, "Componentoriented software development." Communications, ACM, September 1992, pp. 160-165. DOI:10.1145/130994.131005

[13] N.R. Jennings, "An agent-based approach for building complex software systems". Communications, ACM, April 2001, pp. 35-41. DOI:10.1145/367211.367250

[14] T. Erl, SOA Principles of Service Design. Prentice Hall, USA, 608 p., 2008. ISBN 0-13-234482-3

[15] J. Gubbi, R. Buyya, S. Marusic, and M. Palaniswami, "Internet of Things (IoT): A vision, architectural elements, and future directions." Future generation computer systems, Elsevier, September 2013, pp. 1645-1660.

[18] A. Graves, D. Wayne et all. "Hybrid computing using a neural network with dynamic external memory", Nature, Nature Publishing Group, 27 October 2016, pp. 471-476. Doi:10.1038/nature20101

[19] V. Sze, Y.H. Chen, J. Einer et al. "Hardware for machine learning: Challenges and opportunities." In Custom Integrated Circuits Conference (CICC), 2017, IEEE, pp. 1-8.

[20] F. Chen, N. Power and J. J. Collins, "A Stakeholder Contribution Pattern in Requirements Decision-Making: An Empirical Study in Enterprise Development," In 2016 IEEE $24^{\text {th }}$ International Requirements Engineering Conference Workshops (REW), Beijing, 2016, pp. 289-295. Doi:10.1109/REW.2016.054

[21] A. Aurum, C. Wohlin C. "A Value-Based Approach in Requirements Engineering: Explaining Some of the Fundamental Concepts", In Requirements Engineering: Foundation for Software Quality. REFSQ 2007. Lecture Notes in Computer Science, vol 4542. Springer, Berlin Heidelberg, 2007, pp. 109-115.
[22] E. Gelenbe and Y. Caseau, "The impact of information technology on energy consumption and carbon emissions", Ubiquity, ACM, June 2015, 15 p. DOI:10.1145/2755977

[23] J. Spohrer and S.K. Kwan, "Service Science, Management, Engineering, and Design (SSMED): An Emerging Discipline - Outline \& References", International Journal of Information Systems in the Service Sector, IGI Global, July-September 2009, pp. 1-31. Doi:10.4018/jisss.2009070101

[24] E. Lemey and G. Poels, "Towards a Service System Ontology for Service Science", Proceedings of $9^{\text {th }}$ International Conference on Service Oriented Computing (ICSOC 2011), Lecture Notes on Computer Science Service Science, Springer-Verlag, 2011, pp. 250-264.

[25] S.S. Smith, The New International Webster's Comprehensive Dictionary of the English Language - 1999. Deluxe Encyclopedic Edition, Trident Press International, Florida, USA, 1999.

[26] P. Checkland, "Systems thinking". In Rethinking management information systems, Oxford University Press, New York, 1999, pp. 45-56. ISBN 0-19-877532-6.

[27] J. Touzi, F. Benaben, H. Pingaud, and J. P. Lorré, "A model-driven approach for collaborative service-oriented architecture design." International Journal of Production Economics, Elsevier, September 2009, pp. 5-20.

[28] D. Beverungen, O. Müller, M. Matzner, et al. "Conceptualizing smart service systems", Electronic Markets, Springer, Berling Heidelberg, 2017, pp. 1-12. DOI:10.1007/s12525-017-0270-5

[29] J.C. Spohrer, P.P. Maglio "Toward a science of service systems." In Handbook of service science, Ed. Maglio, Spohrer, Kieliszewski. Springer, Boston, MA, 2010, pp. 157194.

[30] P.P. Maglio \& J. Spohrer, "Fundamentals of service science", Journal of the Academy of Marketing Science 36(1), Springer US, March 2008, pp. 18-20.

[31] S. Alter, "Answering Key Questions for Service Science." In Proceedings of the 25th European Conference on Information Systems (ECIS), Guimarães, Portugal, June 5-10, 2017 (pp. 1822-1836). ISBN 978-989-20-7655-3

[32] A. Immonen, E. Ovaska, \& T. Paaso, "Towards certified open data in digital service ecosystems" Software Quality Journal, Springer, 2017. DOI: 10.1007/s11219-017-9378-2.

[33] A. Immonen, E. Ovaska, J. Kalaoja, et al. "A service requirements engineering method for a digital service ecosystem" Service Oriented Computing and Applications, Springer, 2016. DOI: 10.1007/s11761-015-0175-0ds 